\title{
Perceptions, Generalized Anxiety and Fears of Pregnant women about Corona Virus infection in the heart of Pandemic
}

Nazli Hossain ( $\square$ nazli.hossain@duhs.edu.pk)

Dow University of Health Sciences

Mahwish Samuel

The Holy Family Hospital, Karachi, Pakistan

Rekha Sandeep

Dow University of Health Sciences, Karachi, Pakistan

Sadaf Imtiaz

Dow University of Health Sciences, Karachi, Pakistan

Sidra Zaheer

School of Public Health, Dow University of Health Sciences

\section{Research Article}

Keywords: anxiety, pregnancy, COVID 19, Pakistan

Posted Date: May 28th, 2020

DOI: https://doi.org/10.21203/rs.3.rs-32235/v1

License: (c) (i) This work is licensed under a Creative Commons Attribution 4.0 International License. Read Full License 


\section{Abstract}

Background: The current uncertainties and alarming situation of COVID-19 pandemic may cause anxiety, mental distress and fears among pregnant women, who otherwise may have been progressing well. Till date, there is no robust empirical evidence, how the COVID-19 pandemic might have influenced the generalized anxiety and fears among pregnant women.

Objective: To determine the perceptions, anxiety and fears of current COVID-19 pandemic among pregnant women during antenatal and immediate postpartum period.

Setting: Pregnant women attending antenatal outpatient department, or women who recently delivered at the Department of Obstetrics \& Gynecology Unit II, Ruth Pfau KM Civil Hospital and Holy Family Hospital, Karachi were included in the study.

Methods: A pre-designed, validated questionnaire was used by medical doctors through a face-to-face interview to collect the desired information. Associations were determined using parametric tests and a pvalue $\leq 0.05$ was considered as statistically significant.

Results: A total of 286 pregnant women with a mean age of $26.47 \pm 4.81$ years were enrolled in the study. The mean gestational age of women was $33.04 \pm 7.54$ weeks. Majority of women $67.8 \%(n=194)$ perceived that COVID-19 can affect the pregnancy, it can be transmitted to newborn baby $83.2 \%(n=238)$, and can affect the child if mother has infected with this virus $84.6 \%(n=242)$. Most of the women $84.6 \%$ $(n=242)$ were afraid of COVID-19 infection, and reported mean fear level of $5.86 \pm 3.12$ on a scale of 1 to 10. Women who perceived that COVID-19 can affect the child had significantly higher level of GAD scores $(n=37,15.3 \%, p$-value 0.042$)$. Similarly, women who were afraid of COVID-19 infection had significantly higher ( $n=40,16.5 \%$, $p$-value 0.046$)$ GAD score. Women who had high GAD score $(\geq 7)$ also had significantly higher ( $p$-value 0.020$)$ fear score $(6.90 \pm 3.23$ vs $5.68 \pm 3.07)$ compared with women who had normal GAD score $(<7)$.

Conclusion: High proportion of women had stronger belief that if mother have infection, child will also have it and it's likely to be transmitted from mother to child. Although there is not enough evidence to support vertical transmission of infection as yet but it is still appearing as a major stressor among pregnant women.

\section{Background}

Corona virus disease (COVID-19) is a newly emerged respiratory illness, which has spread in 210 countries of the world and declared as a pandemic by the World Health Organization (WHO). The global estimates of incidence and mortality are rapidly changing and till date nearly a quarter of a million are dead due to COVID-19 infection(1). The COVID-19 infection has cause considerably high mortality among those who were older, had comorbidities and were immune-compromised(2). Currently, we do not have 
any global estimates that how many pregnant women have been affected with COVID-19 and how the infection might have influenced their pregnancy, the baby and the mother.

Pregnancy is naturally a period of immunosuppression, in order to protect fetus. Immune response is also not quite consistent during pregnancy rather varies during three trimesters of pregnancy. Women who are in early pregnancy during this pandemic might face different maternal and perinatal outcomes compared to those who are towards the end. During the current pandemic, protective measures recommended by different organizations are same for both pregnant and non-pregnant women. The virus has caused tremendous anxiety and fear about continuation of pregnancy, effects on newborn and chances of vertical transmission(3). In this context the fear of isolation in case of a positive result for COVID-19 is also an important question and concern among pregnant women(3). These concerns are relevant, if one looks at the maternal and perinatal outcome of previous influenza outbreak. In the previous epidemic of Severe Acute Respiratory Distress Syndrome (SARS), the case fatality rate was as high as $25 \%$ without risk of vertical transmission in newborns (4).

Pregnant women worries and concerns are fairly legitimate because any of their own suffering, can negatively influence the fetus as well. There are increased chances of miscarriage, adverse pregnancy outcomes like preterm birth, small for gestational age and intrauterine demise. A meta-analysis of studies looking at fetal outcome during previous influenza pandemic, found an increased rate of preterm delivery(5). For the current pandemic, we have very limited evidence available as yet and that too is in the form of case series and reports with small sample sizes. In a series of 09 pregnant women with diagnosed COVID-19, fetal distress was observed in two cases and all nine live births had good perinatal outcomes(6).Women may delay going to hospital in order to avoid exposure to themselves and family members, resulting in further intra partum complications.

Generally, pregnant women exhibit some form of stress and anxiety during pregnancy, about perinatal outcome. This has resulted National Institute for Health and Care Excellence (NICE) guidelines for mental health of pregnant women during antenatal and postnatal period. Generally anxiety disorders are common psychiatric condition, with life time prevalence of around $28 \%$ in general population(7). Among others, the generalized anxiety disorder (GAD) during pregnancy is common and estimated to be around $8.5 \%(8)$, while its prevalence varies between $4.4 \%$ to $8 \%$ during postpartum period(9). Anxiety disorders in the perinatal period have been found to be associated with depression in later years of life. In these challenging times associated with COVID-19, when there are several social and environmental disruptions, the pregnant women might feel further anxious and fearful about their pregnancy, their own health and the fetus. To the best of our knowledge, there is no study published on anxiety and fear associated with COVID-19 among pregnant women and factors associated with it. Therefore, the aim of the current study was to determine the perceptions, anxiety and fears of current COVID-19 pandemic among pregnant women during antenatal and immediate postpartum period.

\section{Methods}


This study was conducted at two major hospitals of Karachi - the capital of Sindh Province and metropolitan city of Pakistan. Ruth Pfau KM Civil Hospital is a tertiary care teaching hospital affiliated with Dow Medical College. The annual delivery rate at the unit is approximately 5000 per annum. The major turnover of patients in this setting is mainly low-middle income population of both urban as well as rural areas of province of Sindh. The second hospital included in this study was the Holy Family Hospital which is a secondary care hospital ran by The Karachi Holy Family Society, and managed by the Cardinal. The annual delivery rate at this setting is approximately 2400 deliveries per annum with a major proportion of low middle-income families of the region.

\section{Study sample}

All pregnant women who were examined in the antenatal clinics of both hospitals or in the postnatal ward within 24 hours after delivery were invited to take part in this study. A trained doctor explained them about the process of research study and expectations from them as a participant, those agreed to participate after informed verbal consent were included in the study. Pregnant women with any known psychiatric illnesses and those who had history of intrauterine demise or who gave birth to anomalous baby were excluded from this study. These subjects took part in the study, mainly during the $6^{\text {th }}$ April 2020 till $20^{\text {th }}$ April, 2020.

\section{Data collection tools}

After informed consent, a self-designed questionnaire with four main parts was filled by obtaining information from eligible participants through a face-to-face interview by trained medical doctors posted at Units. First part of questionnaire mainly focused on demographic details, second part explored the knowledge of pregnant women regarding COVID-19, third part dealt with the perception, challenges and response of pregnant women towards the current situation of COVID 19 pandemic, including fear about the pandemic. The last part of questionnaire utilized the GAD-7 anxiety scale to assess the anxiety levels of pregnant women. GAD questionnaire was translated into local languages for easy and clearer understanding of subjects. The information was coded and filled on excel sheet.

$\underline{\text { Statistical analysis }}$

STATA version 14 was used for data analysis. Descriptive and Pearson Chi-Square analyses were used to determine the associations between stress and anxiety of current COVID-19 pandemic and other independent variables, including demographics, perceptions and knowledge of pregnant women regarding COVID-19, fear and practices of pregnant women towards the current situation of COVID 19 pandemic. In order to identify the mean differences between the groups, Independent t-test and ANOVA tests were performed. Significance level was set at $p$-value $\leq 0.05$.

\section{Results}


A total of 286 pregnant women with a mean age of $26.47 \pm 4.81$ years were enrolled in the study. The mean gestational age of women was $33.04 \pm 7.54$ weeks. Almost all, $97.2 \%$ women had heard about COVID-19, and television was the major source (55.9\%) of information for it. Regarding GAD - a score of less than 7 was considered as normal and a score of equal or above 7 reflected some degree of anxiety and depression. Of the total, $14.3 \%(n=41)$ women had score 7 or more. Detailed socio-demographics of study participants are showed in Table 1.

Majority of women $67.8 \%(n=194)$ perceived that COVID-19 can affect the pregnancy, it can be transmitted to newborn baby $83.2 \%(n=238)$, and can affect the child if mother has infected with this virus $84.6 \%(n=242)$. Most of the women $84.6 \%(n=242)$ were afraid of COVID-19 infection, and reported mean fear level of $5.86 \pm 3.12$ on a scale of 1 to 10 . Overall high proportion of women reported practicing preventive measures against the COVID-19 i.e. $97.6 \%$ women reported that they had been washing their hands frequently, about $82 \%$ women covered their faces and $93.7 \%$ women avoided gatherings. (Table 2)

Pregnant women's perceptions and fears about COVID-19 and their relationship with high GAD score $(\geq 7)$ are shown in table 3. Women who perceived that COVID-19 can affect the child had significantly higher level of GAD scores ( $n=37,15.3 \%$, $p$-value 0.042 ). Similarly, women who were afraid of COVID-19 infection had significantly higher $(n=40,16.5 \%, p$-value 0.046$)$ GAD score. Women who had high GAD score $(\geq 7)$ also had significantly higher ( $p$-value 0.020$)$ fear score $(6.90 \pm 3.23$ vs $5.68 \pm 3.07)$ compared with women who had normal GAD score ( $<7)$. Knowledge of women that they may be imposed a quarantine if they found positive, did not have any effect on GAD score (Table 3). Preventive practices such as hand washing, covering face and avoiding gatherings were prevalent among most women and were unrelated with GAD score (Table 3).

Perceptions, fears and practices of pregnant women, when related to "feeling afraid that something awful might happen", shown that significant proportion ( $n=38,19.5 \%$, $p$-value 0.014$)$ of women felt on several days of week that their pregnancy might get affected and they also felt on nearly all days or more than half days of the week that they are on significantly $(n=38,23.3 .0 \%$, p-value 0.009$)$ higher risk of disease (Table 4). Pregnant women who had fear of contracting Corona virus infection were significantly feeling more afraid that something awful might happen on nearly all days or more than half days of the week compared to women who had no fear of contracting Corona virus infection $(20.7 \%$ vs $9.7 \%$, p-value 0.002). Other COVID-19 related fears and preventive practices were unrelated with "feeling afraid that something awful might happen" (Table 4)

\section{Discussion}

This study shows that six out of ten pregnant women think that they are at increased risk of COVID-19 infection. Furthermore, more than eight out of ten women perceive that if mother has infection then child can also get infected, and the virus can transmit from mother to the baby. Despite that nearly all women had good preventive practices including hand washing, covering their faces and avoid gathering, most women were still afraid of the COVID-19 infection. Their perceptions that COVID-19 can affect pregnancy 
and they are at higher risk of infection were significantly associated with the fear that something awful might happen. The fear of acquiring infection was also significantly linked with the fear of unknown on most days of the week for these pregnant women.

Although, anxiety disorders are common in perinatal period, whereas depression is much more common in postpartum period(10). This study was an effort to examine, how this global phenomenon of COVID-19 influence anxiety and fears among pregnant women right at the heart of the pandemic. Nearly $14 \%$ of the pregnant women had GAD score ${ }^{3} 7$ in this study which is fairly higher than the previously known rates of between $4.4 . \%$ to $10 \%$ in perinatal period and postpartum period, respectively(11). Anxiety during pregnancy is associated with preterm delivery and low birth weight. A meta-analysis of more than 17,000 pregnant women reported a significant increase in preterm birth among women with anxiety disorder (pooled $\mathrm{RR}=1.50,95 \% \mathrm{Cl}=1.33-1.70$ ). Whereas, low birth weight, among 5000 pregnant women was also found to be increased (pooled $\mathrm{RR}=1.76,95 \% \mathrm{Cl}=1.32-2.33$ )(12). Increased anxiety is not only associated with preterm labor and low birth weight, it is also known to affect the fetal neurological development. This has been attributed to the decreased levels of fetal brain derived neurotrophic factor, impacting the neuro development of fetus (13).

Increased risk of infection and transmission of COVID-19 infection from mothers to baby appeared to be the major factors linked with high GAD scores. This fear of acquiring infection among mothers and high GAD scores are ultimately linked with fear of unknown among these women among most days of week. Though there is no robust evidence to support that the infection transmit from mothers to babies, however, limited conflicting evidence exist both against the vertical transmission (14) and also in favor that neonate may be infected in-utero with the virus(15). More robust evidence is needed to make definitive conclusions about mother to fetus transmission of Corona virus.

This study has its own strengths and limitations. First of all, till date there is very limited empirical evidence about stress, anxiety and fears among pregnant women during this COVID-19 pandemic. To the best of our knowledge, this is the first primary research study assessing perceptions, anxiety and fears of pregnant women right in the middle of pandemic. Though, health professionals from other parts of the world have expressed their worries and concerned regarding anxiety and stress of pregnant women during this pandemic, and its possible impact on pregnancy outcomes (18), the current study's main focus was to assess fears and anxiety among pregnant women. However, it would be interesting to see in follow-up studies, how these GAD scores and fears are linked with maternal and neonatal outcomes. Although, our study has a reasonable sample size, however, most women in the study were mainly from low and middle income families and that limits the generalizability of our findings. Pregnant women of more affluent families with better educational status might have different behavioral or mental response to current crisis, which our study couldn't examine. Despite limitations, till date there is no robust empirical evidence on perceptions, anxiety and fears among pregnant women due to COVID-19 pandemic.

\section{Conclusions}


Our findings suggest that a very high proportion of women have stronger belief that if mother have infection, child will also have it and it's likely to be transmitted from mother to child. As there is not enough evidence to support vertical transmission of infection as yet but it is still appearing as a major stressor among pregnant women. Adequate counseling and reassurance of these pregnant women remains the only option in the current scenario which might reduce their anxiety and fears and lead to better pregnancy outcomes.

\section{List Of Abbreviations}

COVID: Corona Virus Disease

WHO: World Health Organization

SARS: Severe Acute Respiratory Distress Syndrome

NICE: National Institute for Health and Care Excellence

GAD: Generalized Anxiety Disorder

ANOVA: Analysis of Variance

\section{Declarations}

\section{Ethics approval and consent to participate}

The study was approved by the Institutional Review Board, Dow University of Health Sciences (IRB \#.IRB1681/DUHS/Approval/2020/). Participants were enrolled after receiving written informed consent. All procedure followed were in accordance with the ethical standards.

\section{Consent for publication}

Not applicable

\section{Availability of data and materials}

All data generated or analysed during this study are included in this published article

\section{Competing interests}

None

\section{Funding}

None 


\section{Authors' contributions}

$\mathrm{NH}$ prepared the proposal, executed it and shared write up with KS. KS conceived the idea, designed questionnaire, SZ given statistical input, interpretation of results and result write up. MS, RS and SI collected the hospital data. MS was responsible for data entry.

\section{Acknowledgements}

The authors would like to thank the personnel for all the logistic support. We would also like to thank all study participants.

\section{References}

1. Organization WH. Corona Virus Disease, Situation Report-99.https://www.who.int/docs/defaultsource/coronaviruse/situation-reports/20200428-sitrep-99-covid-19.pdf?sfvrsn=119fc381_2 Accessed on 29-04-2020

2. Lei S, Jiang F, Su W, Chen C, Chen J, Mei W, et al. Clinical characteristics and outcomes of patients undergoing surgeries during the incubation period of COVID-19 infection. EClinicalMedicine. 2020:100331.

3. Fakari FR, Simbar M. Coronavirus Pandemic and Worries during Pregnancy; a Letter to Editor. Archives of Academic Emergency Medicine. 2020;8(1).

4. Wong SF, Chow KM, Leung TN, Ng WF, Ng TK, Shek CC, et al. Pregnancy and perinatal outcomes of women with severe acute respiratory syndrome. American journal of obstetrics and gynecology. 2004;191(1):292-7.

5. Littleton HL, Breitkopf CR, Berenson AB. Correlates of anxiety symptoms during pregnancy and association with perinatal outcomes: a meta-analysis. American journal of obstetrics and gynecology. 2007;196(5):424-32.

6. Chen H, Guo J, Wang C, Luo F, Yu X, Zhang W, et al. Clinical characteristics and intrauterine vertical transmission potential of COVID-19 infection in nine pregnant women: a retrospective review of medical records. The Lancet. 2020;395(10226):809-15.

7. Kessler RC, Berglund P, Demler O, Jin R, Merikangas KR, Walters EE. Lifetime prevalence and age-ofonset distributions of DSM-IV disorders in the National Comorbidity Survey Replication. Archives of general psychiatry. 2005;62(6):593-602.

8. Sutter-Dallay AL, Giaconne-Marcesche V, Glatigny-Dallay E, Verdoux H. Women with anxiety disorders during pregnancy are at increased risk of intense postnatal depressive symptoms: a prospective survey of the MATQUID cohort. European Psychiatry. 2004;19(8):459-63.

9. Wenzel A, Haugen EN, Jackson LC, Brendle JR. Anxiety symptoms and disorders at eight weeks postpartum. Journal of anxiety disorders. 2005;19(3):295-311.

10. Ross LE, McLean LM. Anxiety disorders during pregnancy and the postpartum period: A systematic review. The Journal of clinical psychiatry. 2006. 
11. Misri S, Abizadeh J, Sanders S, Swift E. Perinatal generalized anxiety disorder: assessment and treatment. Journal of Women's Health. 2015;24(9):762-70.

12. Ding X-X, Wu Y-L, Xu S-J, Zhu R-P, Jia X-M, Zhang S-F, et al. Maternal anxiety during pregnancy and adverse birth outcomes: a systematic review and meta-analysis of prospective cohort studies. Journal of affective disorders. 2014;159:103-10.

13. Uguz F, Sonmez EO, Sahingoz M, Gokmen Z, Basaran M, Gezginc K, et al. Maternal generalized anxiety disorder during pregnancy and fetal brain development: a comparative study on cord blood brain-derived neurotrophic factor levels. Journal of psychosomatic research. 2013;75(4):346-50.

14. Schwartz DA. An analysis of 38 pregnant women with COVID-19, their newborn infants, and maternal-fetal transmission of SARS-CoV-2: maternal coronavirus infections and pregnancy outcomes. Archives of pathology \& laboratory medicine. 2020.

15. Alzamora MC, Paredes T, Caceres D, Webb CM, Valdez LM, La Rosa M. Severe COVID-19 during Pregnancy and Possible Vertical Transmission. American Journal of Perinatology. 2020.

\section{Tables}


Table 1: Socio-demographics and maternal characteristics of study women $(n=286)$

Characteristics

\begin{tabular}{|c|c|c|}
\hline \multicolumn{3}{|l|}{ Age in years } \\
\hline Mean \pm SD & \multicolumn{2}{|c|}{$26.47 \pm 4.81$} \\
\hline Range & \multicolumn{2}{|c|}{$16-40$} \\
\hline \multicolumn{3}{|l|}{ Gestation age in weeks } \\
\hline Mean \pm SD & \multicolumn{2}{|c|}{$33.04 \pm 7.54$} \\
\hline \multirow[t]{2}{*}{ Range } & \multicolumn{2}{|c|}{$5-40$} \\
\hline & $\mathrm{n}$ & $\%$ \\
\hline \multicolumn{3}{|l|}{ Abortion $(n=270)$} \\
\hline None & 218 & $80.7 \%$ \\
\hline One & 27 & $10.0 \%$ \\
\hline$\geq$ Two & 25 & $9.3 \%$ \\
\hline \multicolumn{3}{|l|}{ Parity } \\
\hline 0 & 90 & $31.5 \%$ \\
\hline 1 & 73 & $25.5 \%$ \\
\hline $2-3$ & 88 & $30.8 \%$ \\
\hline$\geq 4$ & 35 & $12.2 \%$ \\
\hline \multicolumn{3}{|l|}{ Education level } \\
\hline No education & 62 & $21.7 \%$ \\
\hline Primary & 22 & $7.7 \%$ \\
\hline Secondary & 129 & $45.1 \%$ \\
\hline Higher & 73 & $25.5 \%$ \\
\hline \multicolumn{3}{|l|}{ Employment status } \\
\hline Housewife & 276 & $96.5 \%$ \\
\hline Working & 10 & $3.5 \%$ \\
\hline \multicolumn{3}{|l|}{ Are you here for your routine checkup? } \\
\hline Yes & 168 & $58.7 \%$ \\
\hline No & 118 & $41.3 \%$ \\
\hline \multicolumn{3}{|l|}{ Are you here for delivery? } \\
\hline Yes & 129 & $45.1 \%$ \\
\hline No & 157 & $54.9 \%$ \\
\hline \multicolumn{3}{|l|}{ Heard about Corona Virus Disease } \\
\hline Yes & 278 & $97.2 \%$ \\
\hline No & 8 & $2.8 \%$ \\
\hline \multicolumn{3}{|l|}{ Where did you hear about? } \\
\hline Family members & 28 & $9.8 \%$ \\
\hline Television & 160 & $55.9 \%$ \\
\hline Social media & 40 & $14.0 \%$ \\
\hline Friends & 2 & $0.7 \%$ \\
\hline All/ any one of above & 56 & $19.6 \%$ \\
\hline
\end{tabular}


Table 2: Perceptions, fears and practices of pregnant women about COVID-19 ( $n=286)$

Perceptions about COVID

Corona Virus can affect pregnancy?

Yes

No

Don't know n

194

34

58

242

16

28

Don't know

Yes

\section{Don't know}

Do you think you are at increased risk of this disease?

Yes

No

Don't know

Do you think virus can be transmitted to newborn baby?

Yes

No

Don't know

$\%$

$67.8 \%$

$11.9 \%$

$20.3 \%$

$42 \quad 84.6 \%$

$5.6 \%$

$9.8 \%$

$163 \quad 57.0 \%$

$103 \quad 36.0 \%$

$20 \quad 7.0 \%$

\begin{tabular}{|cc|}
\hline 238 & $83.2 \%$ \\
\hline 17 & $5.9 \%$ \\
\hline 31 & $10.8 \%$ \\
\hline
\end{tabular}

Fears about COVID

Do you want to deliver early because of this Corona Pandemic?

$\begin{array}{lcc}\text { Yes } & 50 & 17.5 \% \\ \text { No } & 236 & 82.5 \%\end{array}$

Have you called your family members to be with you during delivery?

Yes

$67 \quad 23.4 \%$

No

219

$76.6 \%$

Were your family members present at the time of previous delivery? $(n=222)$
Yes
196
$88.3 \%$
No
26
$11.7 \%$

Are you aware that quarantine may be imposed if you found to be positive with Corona Virus?

$\begin{array}{lll}\text { Yes } & 165 & 57.7 \% \\ \text { No } & 121 & 42.3 \%\end{array}$

Are you afraid of Corona Virus infection

$\begin{array}{lcc}\text { Yes } & 242 & 84.6 \% \\ \text { No } & 41 & 14.3 \% \\ \text { Don't know } & 3 & 1.0 \%\end{array}$

On a scale of 1 to 10 what is your fear level

Mean \pm SD

$5.86 \pm 3.12$

Preventive Practices

Have you been washing your hands frequently

$\begin{array}{lcc}\text { Yes } & 279 & 97.6 \% \\ \text { No } & 7 & 2.4 \%\end{array}$

Did you cover your face during last 6 weeks i.e. Beginning of this disease

Yes

No

Did you avoid gatherings?

Yes
$81.8 \%$

$18.2 \%$

52 
Page $12 / 16$ 
Table 3: Perceptions, fears and practices of pregnant women about COVID and relationship with Generalized Anxiety Disorder $(\mathrm{n}=\mathbf{2 8 6})$

Perceptions about COVID

GAD-7 Scale

Corona Virus can affect pregnancy?

$\begin{array}{llll}\text { Yes } & 165(85.1) & 29(14.9) & 0.573 \\ \text { No } & 28(82.4) & 6(17.6) & \\ \text { Don't know } & 52(89.7) & 6(10.3) & \end{array}$

If mother has infection, then Corona Virus can affect the child?
Yes
$205(84.7)$
$37(15.3)$
0.042
No
$12(75.0)$
$4(25.0)$
Don't know
$28(100.0)$

Do you think you are at increased risk of this disease?

$\begin{array}{llll}\text { Yes } & 135(82.8) & 28(17.2) & 0.287 \\ \text { No } & 92(89.3) & 11(10.7) & \\ \text { Don't know } & 18(90.0) & 2(10.0) & \end{array}$

Do you think virus can be transmitted to newborn baby?

$\begin{array}{lll}\text { Yes } & 202(84.9) & 36(15.1) \\ \text { No } & 15(88.2) & 2(11.8) \\ \text { Don't know } & 28(90.3) & 3(9.7)\end{array}$

Fears around COVID
n (\%)
n (\%)
p-value

Do you want to deliver early because of this Corona Pandemic?
Yes
40 (80.0)
$10(20.0)$
0.208
No
205 (86.9)
31 (13.1)

Have you called your family members to be with you during delivery?
Yes
61 (91.0)
$6(9.0)$
0.151
No
$184(84.0)$
35 (16.0)

Were your family members present at the time of previous delivery?

$\begin{array}{llll}\text { Yes } & 170(86.7) & 26(13.3) & 0.421 \\ \text { No } & 24(92.3) & 2(7.7) & \end{array}$

Are you aware that quarantine may be imposed if you found to be positive with Corona Virus?

$\begin{array}{llll}\text { Yes } & 142(86.1) & 23(13.9) & 0.823 \\ \text { No } & 103(85.1) & 18(14.9) & \end{array}$

Are you afraid of Corona Virus infection

$\begin{array}{llll}\text { Yes } & 202(83.5) & 40(16.5) & 0.046 \\ \text { No } & 40(97.6) & 1(2.4) & \\ \text { Don't know } & 3(100.0) & - & \\ & \text { Mean } \pm \text { SD } & \text { Mean } \pm \text { SD } & \text { p-value* }\end{array}$

On a scale of 1 to 10 what is your fear level

\begin{tabular}{clll} 
& $5.68 \pm 3.07$ & $6.90 \pm 3.23$ & 0.020 \\
\hline Preventive Practices against COVID & $\mathrm{n} \mathrm{( \% )}$ & $\mathrm{n}(\%)$ & $\mathrm{p}$-value \\
\hline $\begin{array}{c}\text { Have you been washing your hands frequently } \\
\text { Yes }\end{array}$ & $239(85.7)$ & $40(14.3)$ & 0.997 \\
\hline No & $6(85.7)$ & $1(14.3)$ &
\end{tabular}

Did you cover your face during last 6 weeks i.e. Beginning of this disease Yes 200 (85.5) 34 (14.5) 0.842 
No

Did you avoid gatherings?

Yes

No

$228(85.1)$

$40(14.9)$

0.272

p-value calculated using Chi-square or Fisher's Exact test

$17(94.4)$

$1(5.6)$ 
ble 4: Perceptions, fears and practices of pregnant women about COVID pandemic and fear of unknown =286)

Feeling afraid something awful might happen

rceptions about Not at all Several

JVID sure days Over half the days Nearly every day

$\mathrm{n}(\%)$

n (\%)

n (\%)

n (\%)

p-value

Irona Virus can affect pregnancy?

$\begin{array}{llllll}\text { Yes } & 90(46.4) & 66(34.0) & 29(14.9) & 9(4.6) & 0.014 \\ \text { No } & 11(32.4) & 14(41.2) & 5(14.7) & 4(11.8) & \\ \text { Don't know } & 40(69.0) & 10(17.2) & 6(10.3) & 2(3.4)\end{array}$

mother has infection, then Corona Virus can affect the child?

$\begin{array}{llllll}\text { Yes } & 116(47.9) & 78(32.2) & 35(14.5) & 13(5.4) & 0.300 \\ \text { No } & 6(37.5) & 5(31.2) & 3(18.8) & 2(12.5) & \\ \text { Don't know } & 19(67.9) & 7(25.0) & 2(7.1) & -\end{array}$

, you think you are at increased risk of this disease?

$\begin{array}{llllll}\text { Yes } & 68(41.7) & 57(35.0) & 30(18.4) & 8(4.9) & 0.009 \\ \text { No } & 62(60.2) & 30(29.1) & 7(6.8) & 4(3.9) \\ \text { Don't know } & 11(55.0) & 3(15.0) & 3(15.0) & 3(15.0)\end{array}$

, you think virus can be transmitted to newborn baby?

$\begin{array}{llllll}\text { Yes } & 114(47.9) & 77(32.4) & 34(14.3) & 13(5.5) & 0.964 \\ \text { No } & 10(58.8) & 4(23.5) & 2(11.8) & 1(5.9) & 1(3.2)\end{array}$

:ars about COVID

n (\%)

n (\%)

n (\%)

n (\%)

p-value

, you want to deliver early because of this Corona Pandemic?

$\begin{array}{llllll}\text { Yes } & 28(56.0) & 14(28.0) & 5(10.0) & 3(6.0) & 0.674 \\ \text { No } & 113(47.9) & 76(32.2) & 35(14.8) & 12(5.1)\end{array}$

ive you called your family members to be with you during delivery?

$\begin{array}{llllll}\text { Yes } & 44(65.7) & 12(17.9) & 8(11.9) & 3(4.5) & 0.017 \\ \text { No } & 97(44.3) & 78(35.6) & 32(14.6) & 12(5.5) & \end{array}$

ere your family members present at the time of previous delivery? 


$\begin{array}{llllll}\text { Yes } & 102(52.0) & 55(28.1) & 28(14.3) & 11(5.6) & 0.119 \\ \text { No } & 20(76.9) & 3(11.5) & 2(7.7) & 1(3.8)\end{array}$

e you aware that quarantine may be imposed if you found to be positive with Corona Virus?

$\begin{array}{llllll}\text { Yes } & 81(49.1) & 56(33.9) & 21(12.7) & 7(4.2) & 0.583 \\ \text { No } & 60(49.6) & 34(28.1) & 19(15.7) & 8(6.6) & \end{array}$

e you afraid of Corona Virus infection

\begin{tabular}{llllll} 
Yes & $106(43.8)$ & $86(35.5)$ & $36(14.9)$ & $14(5.8)$ & 0.002 \\
No & $33(80.5)$ & $4(9.8)$ & $3(7.3)$ & $1(2.4)$ & \\
Don't know & $2(66.7)$ & - & $1(33.3)$ & - & p-value* \\
\hline & Mean \pm SD & Mean \pm SD & Mean \pm SD & Mean \pm SD & Pal \\
\hline
\end{tabular}

1 a scale of 1 to 10 what is your fear level

\begin{tabular}{llllll} 
& $5.21 \pm 3.25$ & $6.24 \pm 2.63$ & $6.50 \pm 3.20$ & $7.87 \pm 2.94$ & 0.001 \\
\hline eventive Practices & $\mathrm{n}(\%)$ & $\mathrm{n}(\%)$ & $\mathrm{n}(\%)$ & $\mathrm{n}(\%)$ & $\mathrm{p}$-value \\
\hline
\end{tabular}

ive you been washing your hands frequently

$\begin{array}{llllll}\text { Yes } & 138(49.5) & 89(31.9) & 37(13.3) & 15(5.4) & 0.146 \\ \text { No } & 3(42.9) & 1(14.3) & 3(42.9) & -\end{array}$

d you cover your face during last 6 weeks i.e. Beginning of this disease

\begin{tabular}{llllll} 
Yes & $113(48.3)$ & $74(31.6)$ & $34(14.5)$ & $13(5.6)$ & 0.853 \\
No & $28(53.8)$ & $16(30.8)$ & $6(11.5)$ & $2(3.8)$ & \\
\hline
\end{tabular}

d you avoid gatherings?

\begin{tabular}{llllll} 
Yes & $127(47.4)$ & $89(33.2)$ & $38(14.2)$ & $14(5.2)$ & 0.061 \\
No & $14(77.8)$ & $1(5.6)$ & $2(11.1)$ & $1(5.6)$ & \\
\hline
\end{tabular}

ralue calculated using Chi-square analysis

ralue* calculated using ANOVA analysis 